\title{
HOW TO BEST ENSURE REMUNERATION FOR CREATORS IN THE MARKET FOR MUSIC? COPYRIGHT AND ITS ALTERNATIVES
}

\author{
Stan J. Liebowitz \\ University of Texas at Dallas \\ Richard Watt \\ University of Canterbury
}

\begin{abstract}
The focus of this essay is to examine the market for copyrighted works with a particular emphasis on the sound recording market. This market is currently in a state of flux, some would say disarray, due to the ability of the Internet to lower transmission costs for both authorized and unauthorized copies, with the latter being, at this time, far more prevalent. In this essay we discuss the intent of copyright, the role of copying and file-sharing, and some alternative production/consumption schemes meant to strengthen or to replace copyright.
\end{abstract}

Keywords. Copying; Copyright; DRM; Intellectual property; Music; Sound recordings

\section{Introduction}

Digital technologies, particularly the Internet, have had profound effects on the way the business of music is managed. Music performers and writers, as well as the companies and individuals that produce, publish and distribute musical compositions, are increasingly worried that the onslaught of technology is seriously interfering with their ability to charge end users for their creations. The important cost savings that these technologies can bring to distribution and storage activities have had a serious downside in the challenge they impose on the ability of creators to receive remuneration for their work.

Remuneration for creators of musical compositions usually relies on the provisions afforded by copyright - a legal regime that is supposed to define the rights controlled by creators and their delegates. Copyright law, of course, does more than this. By stipulating statutory remedies in cases of infringement, copyright law also provides for a level of enforcement of the established rights; that is, copyright not only defines the right of ownership but it also provides some protection of this right. 
It is becoming increasingly clear, however, that in the face of digital copying, copyright is not functioning as well as it once did. The main problem is not so much in the definition of the set of rights to be allocated to creators, ${ }^{1}$ but rather with the enforcement, or protection, of these rights. The costs of policing infringing behavior are escalating as copying is done outside of organized markets by anonymous strangers, as the copied items are almost perfect substitutes for the original good, and as the very act of copying becomes practically costless. In such an environment, copyright loses its effectiveness as a property right. ${ }^{2}$

Inasmuch as copyright is concerned with imperfect markets, contracting issues, incentive mechanisms, and possible externalities, the study of copyright has been an increasingly popular subject of discussion in the economics literature. Over the past 25 years economists and others have scrutinized many aspects of the relationship between copyright and the production, distribution and consumption of information goods. ${ }^{3}$

The current topic of the day is the impact of file sharing on the music industry. Music has captured the attention of economists for several reasons - because the music industry is undergoing a massive transformation due to transformations in its business model, because music is an international market of substantial economic size (particularly as measured by the importance that music plays in the psyche of man), and because what is happening in the music industry is seen as a likely harbinger of most forms of entertainment, such as movies, computer software, videogames and the like. Many economists have noticed the impending problem; some have argued that with sufficient alterations copyright can meet the challenge while others have argued that copyright should be abandoned altogether since remuneration can be adequately guaranteed by other means. In this paper we attempt to review this literature.

The paper continues as follows: in the next section we give a very short outline of the traditional economic theory of copyright as a remuneration and incentive mechanism for creation. We include within that section an analysis of the literature, now rather extensive, that considers the characteristics that copyright should have if it is indeed to properly address the remuneration and incentive issue. In Section 3 we look at the particular case of the market for music. Concretely, we review the literature that considers the effects of copying of music on the legitimate market. This literature clearly highlights the possible shortfalls of the copyright regime as a mechanism under which creators receive recompense. Then, in Section 4 we consider the literature that discusses possible alternative mechanisms for providing remuneration and incentives to creators. Finally, Section 5 concludes.

\section{The 'Paradox of Creation' and the Basic Economics of Copyright ${ }^{4}$}

The economics of copyright can be summarized as a particular case of private provision of a public good (see Demsetz, 1970). Once a copyrightable creation exists, there is a serious problem in that its consumption is non-rivalrous, in the sense that the product does not get used up upon consumption. For this reason efficient consumption requires that any consumer whose value for the good outweighs the 
(often very low) costs of delivery should be allowed to consume the good-assuming that the intellectual property itself already exists. The price that assures efficient consumption is a price that is no higher than the delivery cost. A price that covers only delivery cost, however, guarantees that the total revenue is insufficient to provide any recompense to the original creator for the (most likely high) initial costs of creation (Arrow, 1962). ${ }^{5}$ Thus a sort of conundrum can exist - efficient consumption precludes efficient production.

In a competitive world without any ownership rights of the intellectual property, the price would be driven down to the costs of delivering the intellectual product to the consumer (which would include the cost of producing any physical embodiment of the intellectual product). Assuming that failure to provide compensation to creators will lead to an inefficiently small production of creative works (and thus inefficiently small consumption of the works not created); such a result would not be socially desirable.

The solution provided by copyright is to award the creator a means of appropriating a sufficient portion of the willingness to pay of consumers for there to be enough incentive for the creative process to go ahead. Copyright is supposed to provide such a mechanism, by establishing the right of the copyright owner to legally exclude free-riders (those who would deliver the intellectual product with no payment to the creator), and this in turn allows the copyright owner to charge a price greater than the delivery cost of the intellectual product. Thus, copyright considers a social balance; the social gain that is derived from the enjoyment of creative goods must be balanced against the inefficiencies that pricing above marginal cost implies. How this is done in practice is often associated with the drawing of an arbitrary 'line in the sand', due both to the inherently theoretical nature of the measures being traded off and to the obvious information problems involved in trying to construct an efficient copyright system (the consumer willingness to pay and the true costs of creation are often not known). Indeed, as Posner (2005, p. 59) states:

Unfortunately, economists do not know whether the existing system of intellectual property rights is, or for that matter whether any other system of intellectual property rights would be, a source of net social utility, given the costs of the system and the existence of alternative sources of incentives to create such property.

Nevertheless, in spite of not having come to concrete answers one way or the other, economists have certainly attempted to address the issues of characterizing an optimal copyright law, and they have also given quite some thought to the issue of alternative sources of incentives. We will now go on to consider this literature in general.

\section{The Optimal Structure of Copyright Law}

The early literature that emerged discussing the issue of the optimal structure of copyright law from an economic point of view questioned the very need for any type of legal protection system (see Plant, 1934; Hurt and Schuchman, 1966; Breyer, 
1970). Written in an epoch in which digital concerns were an unforeseen effect that was still well into the future, this literature appeals to such aspects as the benefits of lead time and stock-piling to dissuade unauthorized copying and distribution of written material (books), as well as to the non-pecuniary motives of creators.

The underlying conclusion of some of these papers is that some protection might be required but the protection from being first was sufficient so that no additional protection in the law was necessary. However, the issues surrounding the distribution and sale of books was very soon to be complicated by new copying technologies that significantly reduced the lead time. These early papers also focused on commercialscale copying and not the private copying that has come to dominate discussions in the more recent decades (photocopying, copying of music to tape cassettes, digital copying of music from and to CDs, and of course, downloading of music and films over the Internet).

Of particular note, perhaps with the early literature, is the issue of the costs associated with copyright protection. The literature clearly identifies the fact that increased copyright protection limits access to socially valuable creations. But furthermore, Plant (1934) also notes that copyright law might lead to an inefficient allocation of resources, in terms of what is now known as 'rent seeking'. Rent seeking presumes that above-normal rents are to be found in an activity, in this case, copyright. The mere existence of a 'copyright monopoly', however, does not imply that any monopoly profits are to be gained, as pointed out by Kitch (2000). ${ }^{6}$ Nevertheless, the possibility of short-term rents or windfalls is often noted for incomplete property rights controlled by the government, as Posner describes the classic treatment (2005, p. 59); '. . by enabling pricing in excess of marginal cost, intellectual property rights attract resources into the creation of such property that may have a larger social product in alternative uses in which, however, they would generate only a competitive return for producers'.

In 1989, Professors William Landes and Richard Posner of the University of Chicago published a seminal paper modelling the economic analysis of copyright law (Landes and Posner, 1989). In their paper, Landes and Posner make a distinction between the economics of copying (which studies the impact of the availability of copies on the demand for originals, and on the welfare of creators and of society in general), ${ }^{7}$ and the economics of copyright per se (which studies the impact of legal copyright protection on the production of, and subsequent access to, creative works). Landes and Posner identify a clear benefit of copyright protection - it addresses the market failure issue of free-riding on creative effort, allowing creators to receive payment, and thereby providing an incentive for more creative products to exist. On the other hand, Landes and Posner identify at least four costs to copyright - the social costs of restricting access to consumers (a static effect, found in each period in which protection ensues), the increased costs of second-generation creation (a dynamic effect, affecting the inter-temporal sequence of creative activity ${ }^{8}$ ), the 'rent seeking' resource allocation problem alluded to above, and the transactions costs of maintaining the system (mainly protection and enforcement costs). The literature on the economics of copyright has attempted to identify the correct balance between these costs and benefits. 
Almost all of the subsequent literature (and indeed, some papers that predate Landes and Posner by a few years) on the balance of the costs and benefits of copyright protection have attempted, in one way or another, to arrive at an 'optimal' configuration of copyright (see, for example, Novos and Waldman, 1984; Pethig, 1988; Besen and Kirby, 1989; Koboldt, 1995; and more recently Yoon, 2002). Basically, the argument assumes that copyright is adequately enforceable (as most models assume that property rights are enforceable), and so the creator is indeed able to reduce copying to the extent that he can sell to a legitimate demand curve at a price that exceeds marginal cost. Given that, the objective is then to attempt to identify the set of parameters that define a socially optimal balance of the costs and benefits of the grant of copyright.

Since the true product demand, the temporal pattern of demand, and the supply curves for creation are impossible to locate, ${ }^{9}$ no fully convincing paper on the optimal level of protection has yet been written. However, most papers that have addressed this issue conclude that an 'optimal' balance of the effects will imply a level of protection that is neither infinite nor zero. ${ }^{10}$

The issue of whether or not copyright law does confer monopoly power of any real consequence has been debated in the literature. Of course, the right granted is still a property right, and so the 'monopoly power' that copyright grants is really no more than the monopoly that we hold over any private possessions (on this issue, see Liebowitz, 1981; Easterbrook, 1991). Any inherent monopoly power must reside in the product with the property right, not in the property right itself. Second, the models typically assume that copyright law allows the creator to sell as a monopolist to a legitimate demand curve, but does not exclude the possibility of free entry. Third, some unauthorized copying still occurs, and so legitimate copies (normally called 'originals') may have to compete with illegitimate copies. Thus market power, as economists typically know it, may be severely eroded, and it is possible that the appropriate setting may be one of monopolistic competition (see Yoo, 2004). Finally, in the case of copyright, without the grant of copyright there is a clear danger that far too little creation will exist, so the 'deadweight loss' from equating marginal cost to a downwards sloping marginal revenue is productive, to use the terminology of Liebowitz and Margolis (2005). That is to say, we should not really compare social welfare under copyright with the social welfare that would occur under an ideal situation. Instead, we should compare it to the best social welfare that can actually be achieved, and if copyright is the best solution, the deadweight losses associated with generating payments required to compensate the author are not social losses at all.

Aside from the costs of limiting access, the literature has also mentioned, although to a lesser extent, the fact that a system of copyright protection implies its own set of transactions costs, ${ }^{11}$ the costs of administering and enforcing the copyright that is granted. The transactions costs of enforcement were explicitly noted by Landes and Posner, as were the 'lobbying' costs associated with rent-seeking activity as different groups appeal to the authorities for legislative change. Also present are the costs associated with negotiating, writing and enforcing contracts for the subsequent exchange or transfer of intellectual property (see Cheung, 1970). It is also worth 
noting here that the existence of copyright collectives - large groups of copyright holders who administer their intellectual property together - is based mainly on a transactions costs savings argument (see Hollander, 1984; Smith, 1986; Besen et al., 1992).

When taking into account all of the costs and benefits conferred by copyright law, there remains the question of exactly what are the 'optimal' parameters to apply (for an interesting selection of papers, mostly unpublished, on this general issue, see Farrell, 1994; McCain, 1994; Thorpe and Rimmer, 1995; CPB Netherlands Bureau for Economic Policy Analysis, 2000; Siebrasse and McLaughlin, 2001). In particular, however, the question of the best duration of copyright has been hotly debated over the years. Of course, we have already mentioned some of the early literature (Plant, 1934; and more recently Boldrin and Levine, 2002. See also the historical perspective on this issue in David, 1993) that suggested that there was really no need for legal copyright protection at all (and so the optimal duration was in fact whatever being first provided). This contrasts with another group of papers that argue that not only should copyright exist, but there are arguments to support it lasting forever (Turnbull, 1998; Landes and Posner, 2002). In any case, the alterations in the duration that legal systems provide add more fuel to the academic debate, and invariably lead to a flourishing of new papers on the issue of the optimal duration of copyright protection - in particular see Ginsburg et al. (2000), Akerlof et al. (2002) and Liebowitz and Margolis (2005).

Much of this literature focuses on the theoretical aspects of copyright, such as the possible impact of laws that create changes far in the future whose present value would appear to be exceedingly small. What is lacking are detailed empirical analyses. There is at least a trickle of such analyses with Rappaport (1998), Liebowitz and Margolis (2005) and a more thorough examination by Baker and Cunningham (2006).

\section{The Effectiveness of Copyright Law in the Market for Music}

In spite of copyright law protecting the interests of creators and authors during its term, copyright infringement is clearly present, and indeed is currently at levels that are extremely troublesome (Liebowitz, 2006a). A large and unanticipated increase in copyright infringement could be taken as evidence that that copyright law is not functioning as intended, and thus the design of the system might need to be addressed.

The main questions to be considered are whether or not the current level of copyright infringement is significantly eroding creation, ${ }^{12}$ and whether or not such erosion (assuming it exists) is socially inefficient or not. There are several possible ways in which infringement might be socially efficient (see, for example, Watt, 2004, for a brief mention of some of these), and might even have a positive effect upon the amount of secondary creation that takes place. First, of course, we have the fact that, since private infringement takes place at prices below the legitimate market price, it allows consumption by individuals that have a willingness to pay below the market pricing allowed by copyright. In this way, infringement reduces 
the consumption deadweight loss, and if infringement were only engaged in, say, by those with values below market pricing, society as a whole would gain.

Second, as far as the erosion of creative works is concerned, if copying were to affect all creators proportionally, then the first to defect to alternative employment would be those earning the lowest economic rents - those artists whose value outside of music is very close to their value as musicians. The social value of the loss of such creators might not be high. Third, it is clear that copying networks such as file sharing might constitute a method of free advertising for as yet unheralded artists without record contracts, and such copyright infringement, by promoting such networks, may create a positive impact for newcomers, since the costs of distribution are so much cheaper. Of course, some of the lost revenues come from record companies who have fewer resources to pay for those acts that mostly turn out to be dry holes, so a decline in revenue due to copying networks will be expected to have a corresponding decrease in new acts that otherwise would have landed a record contract.

Finally, the most likely scenario is that the groups of artists that are hardest hit (both in absolute and relative terms) by copyright infringement are those with super-star status and incomes. However, these individuals are likely to be earning large economic rents so the effect of lost dollars to these artists might have little impact on their creative works.

In any case, it is extremely difficult to correctly and convincingly answer the types of questions that are of interest as far as the relationship between infringement and creation is concerned, and indeed the literature has not yet made any truly rigorous attempt to address them. However, much attention has been paid to the very closely related issues of exactly how much of an effect copyright infringement has upon the legitimate market, especially for the case of musical compositions.

The first aspect of infringement that was seriously considered in the economics literature was the calculation of the degree to which infringement represented lost sales of originals. That this was considered to be worthy of study was mainly due to the outcries of copyright holders (for example, the record industry - see the data in the IFPI Report on Piracy (2003)), with claims that infringement represents lost sales almost as great as the total legitimate trade itself. ${ }^{13}$ As was clearly shown in a quite general theoretical setting by Besen and Kirby (1989), since copies are priced below originals, many consumers of illegitimate copies would not likely consume originals even if copies were not available (see also the analysis in Watt, 2004).

Reliable estimates of the proportion of copies that represent lost sales are difficult to come by, but the early literature (before online file sharing and downloading were an issue) suggested that for the case of music the figure was closer to $40 \%$ (see, for example, Mannering, 1994, who gives a figure of 38\%, and Warner Communications Inc., 1982, which rounds it off to 40\%). Besen (1987) cites research done by Alan Greenspan for the Recording Industry Association of America in which it is estimated that about $40 \%$ of home taping of pre-recorded music represented displaced legitimate sales, and research done by G. Davis for the International Federation of Phonogram and Videogram Producers suggests that $25 \%$ of home taping of LP records represented lost sales of originals. 
The early literature on the effects of copying on the pre-recorded music industry is often represented by two papers - Belinfante and Davis (1979) and Widdows and McHugh (1984). Both of these papers conclude that piracy and copying of music had only a small negative effect upon sales and profits of the music industry, and one that was considerably smaller than had been claimed by music industry officials. Indeed, these two papers found that other factors, such as demographic change and the general state of the economy were more likely than piracy to have caused the downturn in sales of the latter part of the 1970s.

Modern treatments of the effects of physical copying upon the demand for music are more difficult to come by, as modern authors have concentrated much more on the case of downloading and file sharing (see below). However, quite recently Hui and Png (2003) estimate that, worldwide, about $6.6 \%$ of the CD copying that takes place in for-profit counterfeit markets represents lost sales in the legitimate market.

Physical copying of music has also been examined recently using experimental data. For example, Maffioletti and Ramello (2004) shed light upon the microeconomic behaviour of potential consumers of copied CDs using an experiment with a population of 188 Italian university students, using both hypothetical and real choices. In their paper, Maffioletti and Ramello find that, first, the mean willingness to pay for a legitimate CD is typically below the market price (between about $60 \%$ and $80 \%$ of the full market price). This result, if true, would imply that very few of their students actually would purchase any CDs, which seems slightly strange in a world where most students would be expected to have collections of CDs. ${ }^{14}$ The second result was that the mean willingness to pay for a copied (i.e. illegitimate) music CD, while significantly greater than 0 , is only about a third to one half of the willingness to pay for a legitimate $C D{ }^{15}$ If these results reflected the entire population of potential purchasers, they would imply that the recording industry underestimates the elasticity of its demand curve and would likely benefit from lower prices.

Also, recently, Bounie et al. (2005) have made an attempt to provide the separation of the substitution and complementary effects using survey data from French university students. They find much interesting evidence relating to stated CD purchases, MP3 files, and the size of CD collections. They also suggest the novel idea of using the answer to a question about how many MP3 files are deleted from hard drives as a measure of the degree of sampling. Their statistical analysis shows that overall, using file sharing networks and having more MP3 files lead to a decline in CD sales. This is particularly true for the larger subgroup that does not delete MP3 files. For the smaller group identified as 'samplers', the impact of downloading files on $\mathrm{CD}$ sales is ambiguous, which, as we explain below, is as theory predicts.

\subsection{Examining the Impacts of File Sharing}

For the interesting case of digital file sharing for music, a recent literature has emerged. This literature was initiated, in a modest way, at the Napster trial, in which the plaintiff commissioned a study (see Fine, 2000) to estimate the effect 
of online file sharing upon the sales of physical music on CDs. The study, which compared point-of-sale data in brick and mortar record stores located within a small radius of universities in the USA (since it was considered that university students were more likely to engage in downloading than the rest of the population), and compared sales to the overall sales of CDs at retail both before and after Napster was available. The study found that from the first quarter of 1999 (Napster did not exist) to the first quarter of 2000 (Napster did exist), while nationwide sales of CDs grew by some $6.6 \%$, sales near universities dropped by $2.6 \%$. Thus it might seem that the study provides some evidence for a negative effect upon sales being caused by downloading. However, the study found very similar results in the period from 1998 to 1999 when Napster did not exist, casting serious doubt on how to interpret these results. One possibility was simply that college students were more likely to order CDs online during this period so that sales in local stores fell, but not because of file sharing. It was also the case that in the first quarter of 2000 Napster was still very small, being only one seventh the size it would reach in the first quarter of 2001 .

As is often the case, the economic impact of Internet downloading and file sharing can have various theoretical impacts. There are four possible impacts that have been discussed in the literature:

1. First, downloading can be an activity that substitutes for legal sales due to digital media providing a very high degree of substitutability of the two products. The impact of this substitution is unambiguous and it is difficult to imagine that the substitution effect is not fairly large when the copy is a good substitute for the original.

2. Second, it is possible that some file sharing and downloading is motivated by sampling (trying before one buys), and the ability by consumers to purchase more precisely targeted products can alter the legitimate sales, although in uncertain ways. Analysts have tended to focus on the positive possibility of sampling, leading them to a more positive view of it than they should have. In fact, sampling will rotate the demand for CDs clockwise, raising the value of early CD purchases but lowering the value of later purchases because there is little time left to listen to additional CDs, say, because the early CD purchases were listened to so intently. In fact, empirical work is needed to determine whether the typical impact of sampling on sales is positive or negative.

3. There is a set of models based on network effects (Conner and Rumelt, 1991; Takeyama, 1994), which suggest that network effects might alter the impact of copying on sellers of originals. This has been applied to music by Gayer and Shy (2005). The basic intuition is that purchasers of CDs might have higher values for CDs depending on the number of other people listening to music, implying a positive network effect for music listening. Whether there are such network effects is unknown. If there were such network effects, and if file sharing increased the overall music listening among those who otherwise were unlikely to purchase CDs but who still provide positive network effects to those who do, then the demand for CDs on the part of purchasers would 
increase. Given the rather restrictive conditions required for this process to work, and given the fact that radio has always been a freely available source of music, it seems problematic that file sharing could increase music listening and generate positive network effects sufficient to increase demand to any significant extent.

4. One final possible factor involved with copying is indirect appropriability, which is discussed in more detail in Section 5 of this paper. Indirect appropriability allows the seller of originals to target alterations in the price of originals because the value of the copies is indirectly transmitted to the seller by way of higher valuations from those making copies. As discussed in Liebowitz (2002), indirect appropriability does not seem capable of having any impact on file sharing. The reason is that neither of the two conditions, which would allow indirect appropriability to work, hold - there is great variability in the number of copies made from each original, and it is not possible to identify those originals that have copies made and charge higher prices for them.

Given the theoretical analysis it is not surprising that most empirical work finds a negative impact of file sharing on sales of sound recordings.

The papers that have examined the impact of file sharing can be categorized by result and by methodology. By results the classification is quite simple. There is one study (Oberholzer and Strumpf, 2004) that claims to find a zero impact, although an outside reading of both versions of their paper could lead one to conclude that they actually find a positive relationship. All the other studies find some degree of negative relationship between file sharing and sales of sound recordings. These latter studies can be classified into those which find that file sharing caused some portion of the decline but not the entire amount and other studies that are consistent with file sharing causing the entire decline, or more, as explained below. Since many studies have a range of results, this latter distinction will be made apparent when the studies are categorized by methodology, an endeavour to which we now turn.

\subsubsection{Using Countries or Cities as the Unit of Analysis}

There are several papers that take this approach. The idea is straightforward enough: compare changes in sales of sound recording in different geographic locations over time using some measure, such as the share of Internet users, to proxy for the impact of file sharing across these regions.

Liebowitz (2006b) examines how the change in the sales of CDs in 99 US cities is impacted by file sharing as proxied by Internet access, and several demographic variables. Using Internet access as a proxy for file sharing (but after removing the impact of Internet usage on generic entertainment activities) he finds that cities with high levels of file sharing have had considerably larger decreases in CD sales than other cities over the period 1998-2003. The coefficients are of sufficient size to support a conclusion that file sharing could explain the entire decline in sales plus an implicit growth in sales that never materialized. Peitz and Waelbroeck (2004) use 
data from 16 countries for the period 1998-2002. They find a $20 \%$ decline in the sales of music for the world due to file sharing. Zentner (2005) uses international cross-section data from a very large number of countries during the period 1997-1998 to 2001-2002. He finds a worldwide decline of $15 \%$ and a US decline of $30 \%$. Since neither of these papers present direct evidence of how these declines compare with actual declines we do not know how to translate this result into a share of the total decline. Nevertheless, these numbers are quite large and generally in the vicinity of the entire decline in many countries.

The difficulties with the geographic approach used by these authors include the fact that there are many factors that differ across geographic areas that are difficult to account for in these regressions. In some instances these areas have different levels of organized piracy, speak different languages, and have very different levels of per capita income, CD sales, Internet use, and stereo equipment. For example, CD writers make downloaded music much better substitutes for the purchase of a CD. In countries (or cities) where there are fewer CD writers per computer, downloading will have a smaller impact on sales. Statistics on the number of CD writers are frequently difficult to come by, thus potentially clouding any analysis. Attitudes towards piracy are also likely to differ by geographic area, which is another difficult variable to control for. Finally, the sizes of the data sets are usually quite small because the number of geographic areas with data on file sharing/Internet use is not large.

\subsubsection{Using Records as the Unit of Analysis}

There are two papers using this approach - one by Oberholzer and Strumpf (2004) and a dissertation at Harvard by Blackburn (2004). Both observe CD sales in the United States. Oberholzer and Strumpf were allowed access to actual downloads logs on a server that was part of a file-sharing system, whereas Blackburn used data provided by Big Champagne. Oberholzer and Strumpf have the advantage of having actual downloads but the disadvantage of having information from only a single small part of the file-sharing world. Blackburn's data are based on the entire industry but do not directly measure downloads - instead, it is based on the number of files available on hard drives for individuals to download. Both papers assume that their samples are representative of the entire market and provide some evidence to support this view. Both papers then match their estimates of music downloads to the recordings where the songs appeared and then both papers use data from SoundScan to compare the downloads of CDs to the sales of CDs. Nevertheless, these two papers come to diametrically opposed conclusions.

Each paper finds that for the average $\mathrm{CD}$, file sharing has a negligible impact. Of course, it is incorrect to give each CD equal weight if the purpose of the analysis is to determine the overall impact of file sharing on CD sales since a small number of popular CDs are responsible for the lion's share of industry sales. Blackburn interacts a measure of prior artist popularity with his measure of downloading and finds that file sharing has a positive impact on relatively unknown artists, but more importantly, has a strong negative impact on CDs from more popular artists, 
leading him to conclude that file sharing has a large negative impact on record sales. Oberholzer and Strumpf used two different techniques to determine how their measured impact differed by type of album. In the original version of their paper they divided their sample into quartiles based on how successful the album was in the market, and found that file sharing had a small, insignificant negative impact on the less successful albums but a fairly large positive impact that was on the border of significance for the more successful albums. Their newer version of the paper removes the tables providing details of the regression results by quartiles. Instead, the authors use an interaction term (based on prior popularity) similar to that of Blackburn and produce a result strikingly at odds with their prior analysis: now the more popular artists are negatively impacted by file sharing, although, contrary to Blackburn's results, they are not significant.

There is a potential fallacy of a composition problem and also seriously difficulties with simultaneity. The reader is referred to Liebowitz (2005a) for a detailed discussion of these issues.

\subsubsection{Using Surveys}

There are several papers based upon surveys. Both Hong (2004) and Michel (2005) use data from the US Consumer Expenditure survey. Rob and Waldfogel (2006) use data based on a survey of American college students and Zentner (2006) uses data based upon a survey of consumers in several European countries.

All of these studies conclude that file sharing is harmful to record sales. Michel finds that file sharing caused a decline that seems small except that it was larger than the actual decline that occurred over his period of measurement while Hong finds that file sharing causes a decline less than half of the measured decline. Zentner finds a decline in the likelihood of purchase, which does not easily translate into a quantity of lost sales. Nevertheless, he provides an estimate of sales loss of approximately $8 \%$ from what they would have been as of 2002, but his results are based on seven European countries and it is not clear whether this change is larger or smaller than the actual change that occurred.

Rob and Waldfogel (2006) find that each downloaded album reduces legitimate sales by at least 0.2 albums (and a much larger amount if their instrumental methods are correct), which is a large enough result that it could explain the entire decline in record sales depending on the amount of file sharing that has actually occurred. They also suggest that file sharing might have a net benefit to society if one ignores the negative consequences of reduced production of creative works caused by lower revenues to the industry.

Surveys can be misleading because respondents may not be representative of the entire population, or they may not know the answers to questions asking for detailed information about purchases, or because they are unwilling to answer questions honestly. Given the highly politicized nature of file sharing, it would not be surprising if respondents tried to minimize their reported reduction in CD purchases. If so, results based on such surveys would be likely to understate the true impact on sales. ${ }^{16}$ 
Zentner and Rob and Waldfogel have direct information about MP3 downloading in their data, whereas Hong uses Internet access as a proxy and Michel uses computer ownership. The two studies with direct measures of downloading attempt to overcome a potential simultaneity problem (due to the fact that those individuals who are most interested in music tend to be heavy purchasers as well as heavy downloaders) with instrumental variables although Rob and Waldfogel report a negative relationship even before attempting to control for simultaneity using instrumental variables.

\section{Alternatives to Legal Copyright Protection}

Parallel to the literature on the economics of copyright, an important series of papers has appeared that considers the ability of creators to appropriate revenue from the market with no appeal at all to copyright law per se. This literature has suggested many ways in which this may be done (see Varian, 2005, pp. 134-136, for a short description of most of them), each of which we will now discuss in turn, and how they pertain to the particular case of music. ${ }^{17}$

Before beginning, however, we should always bear in mind that these suggested alternatives are a type of second-best solution, in the sense that the existence of copying and file sharing might render the first-best (copyright) unworkable. If any of the alternatives were in fact first-best we would have expected them to have been used well before copying became an issue. Digital transmission of copyrightable media, via Internet or even on physical formats, is a superior technology for the delivery of information goods, but it also provides the basis for programs that allow and encourage the erosion of property rights, perhaps even to the point of eliminating any semblance of property right. Without secure property rights market economies cannot function (and non-market economies function very poorly), and that is equally true for the functioning of individual markets. ${ }^{18}$

To begin with, it is important to note that while very closely related, the issues of the optimal structure of copyright law on the one hand and the alternatives to it on the other are often approached in different ways. Concretely, the study of the optimal structure of copyright law almost invariably considers the social trade-off associated with property rights in creative goods, and incorporated into the analyses are the trade-offs associated with creation taking place. Thus the economic analysis of copyright law typically attempts to provide for sufficient incentives for the creator to create, but only just. ${ }^{19}$

On the other hand, most (but not all) of the literature concerning the possible alternatives provides free access to consumers, eliminating the under-consumption problem associated with copyright. The main question for welfare analysis for these models then becomes solving the problem of finding mechanisms that generates the proper set of creative works. There is no attempt to suggest that these mechanisms provide only enough payment, perhaps because, being focused on actual conditions, they eschew the notion of perfection as even being remotely reachable.

Quite generally, the types of non-copyright mechanisms that have been discussed in the literature slot into three general headings: (i) mechanisms that ameliorate the 
difficulties caused by copying, i.e. manners in which copyright holders can take financial advantage of certain aspects of copying, (ii) mechanisms that attempt to reduce or eliminate copying, and (iii) mechanisms that are independent of the amount of copying (that replace copyright). We will discuss each of these options in turn.

\subsection{Mechanisms that Ameliorate Negative Impacts of Copying}

\subsubsection{Indirect Appropriation}

As already mentioned, one strand of literature suggests that when copying is a possibility, then strategies involving re-pricing of the product may be available to creators to extract rents from the market. The seminal paper in this literature is Liebowitz (1985), ${ }^{20}$ in which it is shown that the emergence of the photocopying technology may well have benefited rather than hurt publishers of academic journals. The idea is indeed simple; the ability to copy originals has two effects it reduces the number of originals sold (a substitution effect between originals and copies), but it provides possible indirect appropriation - that is, it may increase the willingness to pay for each original (since more use can be made of it). When price discrimination is possible, or when there is little variability in the number of copies made from each original the additional value that consumers place on originals due to the ability to copy can be appropriated by the sellers.

Indirect appropriability provides a strategy under which copying may actually be of benefit for creators of originals, but the necessary conditions for it to work may often not be present. For example, it requires that the originals that will be subject to copying be clearly identified, and there be some transmission of value from those receiving the copies to those purchasing originals. Indeed, Liebowitz himself (Liebowitz, 2002, 2003) has argued that indirect appropriability is very unlikely to play an ameliorative role in digital file sharing for several reasons. First, there is no transmission of values since the copier and lender have no relationship with one another. Second, the seller of originals cannot identify which will be used to make copies. Third, there is a great variability in the number of copies made from each original. Besen and Kirby (1989), Johnson and Waldman (2005) and Liebowitz (2005b) have also shown that specific market characteristics, which seem to describe file sharing, may ensure that copying always harms creators.

Notwithstanding the possibility that indirect appropriability may not work, there is a small but influential literature, led by Professors David Levine and Michele Boldrin, that asserts that market mechanisms based on appropriate pricing strategies (read, indirect appropriability) will always be an efficient remuneration mechanism (see Boldrin and Levine, 2002). The assumption throughout this literature is that this remuneration will also always suffice as an adequate incentive for creation, and so this literature sees no place for copyright law, except for the first copy. The thesis of Boldrin and Levine is based squarely upon the neoclassical theory of economic growth, and the efficiency of the market mechanism. It is, however, difficult to 
see how the market failures implied by the public good aspects of copyrightable creations are addressed in those models, if indeed they are.

\subsubsection{Network Externalities}

A network externality exists whenever the willingness to pay of any one user of a product is influenced by the number of other users of the same product. Classic examples of network externalities are telephones and fax machines, while computer operating systems (the more users of a common platform, the greater is the value of that platform due to a greater selection of software) and fashion fads are still other examples. $^{21}$

Copyrightable intellectual property is often thought of as being an example of network externalities (see Scotchmer, 2005, chapter 10, for a good general treatment of the case of network externalities in intellectual property). For the case of some software the network effects are clear. It is also possible that there are positive network effects for music in that the more popular a particular artist becomes (where 'popularity' is measured by the number of people who listen to the artist's music, whether or not they actually paid for an original recording) the greater might be the willingness to pay to listen to that music (for example, as measured by the price that can be charged for concert tickets) independent of the consumer's autarky valuation of the product.

It is clearly the case that in the presence of positive network effects, since copying can increase the user base, which in turn might increase the willingness to pay for originals on the part of some users, which it might turn out that copying can work in the copyright holder's favour (see Takeyama, 1994, for a well-known formal model that captures this type of network effect). ${ }^{22}$

Network effects might be important to the music industry as a whole, or not, although it is clear that they are important for individual creative works that benefit from faddish behaviour. What is not clear is whether file sharing increases network effects, if there are any, since consumers had a free alternative in radio before file sharing and there is as yet no evidence whether file sharing actually increases the consumption of music in a manner that might impact network effects. More, or even some, work on this topic is necessary before we can make any strong statements about network effects, music and copying.

\subsubsection{Bundling with Physical Complements, Advertising and Informational Comple- ments}

It is not uncommon to see two items marketed together. Economists use the term 'bundling' to describe this type of practice. As examples of bundling of complementary products, we often see pre-recorded music on CDs sold along with non-copyable (or at least more difficult to copy) items such as the artist's autograph, fan club membership, or some other type of relevant merchandise (posters, tee shirts, options for concert tickets, etc.). More recently, it is becoming common to see easily copyable CD ROMs or DVDs being sold along with much more difficult to copy 
items such as newspapers. Such bundling makes copies less good substitutes and thus weakens the substitution effect.

In a similar vein, but an unbundled one, it is sometimes suggested that the music industry is really a set of complementary activities and that the advent of copying requires a readjustment of the relative prices of the complements. For example, most recording artists also give concert tours. Tours are thought to help sell CDs. ${ }^{23}$ For this reason the price of tours might be set below its individual profit-maximizing level in order to increase sales of CDs. If concerts and CDs were strong complements then one strategy to solve the copying problem would be to raise the price in the non-copyable concert market and lower the price in the CD market. This type of strategy has been suggested by Ku (2002). The problem with these suggestions is that we do not know whether many of these products are even substitutes or complements (e.g. concerts and sound recordings, radio and sound recordings). Further, in order for this strategy to work they need to be very strong complements, on the order of the manner in which left and right shoes are used together. Otherwise, the lost revenues from the market beset with copying cannot be made up in the other market. Of course, we would expect market players to be able to discover this superior strategy on their own. It is also the case that this new strategy would be expected to lead to a solution inferior to the original market organization since it was not chosen prior to file sharing and if it were superior we would have expected it to have evolved on its own in the many decades prior to file sharing.

There is a second type of bundling that can provide some benefit to copyright owners from unauthorized copying - bundling advertising with copyable goods (see Bakos and Brynjolfsson, 1999). The more copies of a given film that circulate, the greater is the value of certain types of advertising that can be inserted in the film. For example, BMW provided vehicles for recent James Bond films, and clearly the more viewers there are of the film, the more can be charged to BMW for this advertising. Thus in this case copying, which might increase (perhaps greatly) the number of viewers, could provide a lucrative source of revenue for the owners of the copyright in the film. Of course, if this had been a superior revenue generation device we would have expected to see the market voluntarily moving in that direction before the advent of file sharing since it was perfectly possible to give away free music or movies before the advent of Napster. Again, the fact that we did not see this behaviour is strong evidence that it was not profit maximizing before file sharing altered the nature of the market.

In a different dimension, we have seen a new business model in software (the Open Source Software movement) that has achieved a great deal of attention far in excess of its current market share. There are suggestions (Fisher, 2004) that this might be a model that can apply to other copyright markets. Yet the staying power of open source is as yet unknown. Neither is the underlying business model fully understood. Although there is a mythology surrounding open source claiming that it is a completely different production process (many more individuals involved in coding and bug fixes), recent research into the creation of open source software suggests that it closely resembles production in more traditional software markets 
and if anything, the creation of open source software is actually more concentrated (Mockus et al., 2002, 2003; Asundi et al., 2006). Even the claim that creators of open source do it for reasons contrary to normal markets is questionable since many of the individuals providing the lion's share of the work are apparently paid to do so by large corporations. The benefits to firms that provide support for the creation of open source comes from the possibility of selling complementary goods, such as hardware, support contracts, or advertising. ${ }^{24}$

Finally, a very interesting case of informational bundling occurs when new artists attempt to advertise themselves via widespread circulation of their creations. The idea is very similar to the reason why record companies often pay radio stations to play new records (this is known as 'payola'; see Liebowitz, 2004, and Coase, 1979) - the more people hear these records, the more likely it is that the records will become popular, and thus the more lucrative becomes the market for them once they are released to the general public. In the case of unknown artists, the more widely they can get their initial creations heard, the more likely it is that they will have a financially rewarding future.

The unknown recording artist example is a case of inter-temporal advertising - facing an unknown opportunity cost in the present (the cost of allowing one's creations to be freely copied) in order to allow for a better future market. However, exactly the same thing occurs for different types of copyrightable products. For example, there are often free versions of software or books with reduced functionality available over the Internet with the more complete versions for sale elsewhere. This strategy of offering different versions of a single item of copyrightable property, with quality differences between versions, is often known simply as 'versioning'. The freely available low-quality versions are supposed to act as advertising for the more expensive high-quality version. ${ }^{25}$

It needs to be kept in mind, however, that although free samples may be beneficial for new market entrants, it is never a profit-maximizing policy for entire markets unless there is some complementary good that is sold at a positive price, which covers the losses on the free good. Even if file sharing helps establish a new musical group, say, it is likely that the sales generated by that new group come at the expense of some other established or up-and-coming group, and that it would be incorrect to generalize this benefit that accrues to a single entity to the entire industry.

These new models are worthy of serious examination. Nevertheless, although the above stratagems provide theoretical possibilities of revenue generation in lieu of traditional copyright, unless we are willing to suppose that the market has failed to find the best model, even over many decades, a supposition we are not willing to make, we must assume that these are inferior to the prior mechanisms chosen by the market that have lasted for generations.

It is possible that the unprecedented degree of copying caused by file sharing has tilted the market so that one of these models will now be superior to the more traditional models. But we need to remember that it is only superior under the new, inferior situation faced by copyright owners. The new result would still be inferior to the old, from the perspective of copyright owners. If, however, some change in 
the market other than the weakening of property rights led to a repositioning of strategies, then the new models would likely be considered superior.

\subsection{Mechanisms that Reduce Copying}

\subsubsection{Strategic, or Limit, Pricing}

Limit pricing is traditionally a strategy for a dominant firm to employ so as to reduce incentives for competitors to enter. It generally requires that price be set at a level such that after the entrance of a competitor, assuming there is some minimum efficient scale required to enter, the price would fall to an unprofitable level. Both the entrant and incumbent would suffer these losses, but since the entrant knows this in advance, entry becomes far less attractive.

One might try to apply such reasoning in copyright markets, where the 'entrant' is the copier. One problem is that limit pricing is not likely to be a successful strategy when the entrant has lower costs. If the incumbent tries such pricing the incumbent will incur greater losses than the entrant.

In a similar vein, organized copyright infringement usually prices its product at a level that provides profits while also selling at a considerably lower price than authorized copies, and although firm evidence on these facts is difficult to come by, the surveys by Maffioletti and Ramello (2004) point to considerably lower consumer valuations for copies. Thus, it is often argued (see, for example, the model in Watt, 2000) that there is a great deal of scope for legitimate producers to reduce their prices, thereby squeezing out piracy by price competition, ${ }^{26}$ rather than turning to a legal devise like copyright law to maintain high prices.

It is not clear that such models provide a rational defence for copyright owners against the onslaught of copying. Some portion of the literature seems to feel that limit pricing is in fact a viable tactic, which implicitly assumes that the advantages to the copier are small. It is not at all uncommon in the literature to find models such that any harm to creators caused by copying is merely the reduction in the producer's surplus and this only occurs when the price lies above the marginal cost of production, at least for the inframarginal units (see, for example, Belleflamme, 2002).

But the cost advantages to a producer of counterfeits are much greater than normally acknowledged. There are at least four important costs that are neglected in such models that are ignored at our peril. The first is the direct cost associated with the payment to the author by the book publisher or record company, which is the one cost that is most likely to be acknowledged. Second are the costs associated with the losses incurred by the majority of books, records, and movies, which must be quite large since there are many more unsuccessful than successful works. Third, there are the costs associated in wading through the large number of possible musical groups that are not given recording contracts and manuscripts that are not purchased. Fourth, there are the costs of advertising and promoting the works, costs that the copier is perfectly capable of free-riding upon. 
To the extent that any focus is given to cost disadvantages held by legitimate firms, only the payments to the creator of the single product are generally noted as a differential cost that must be covered. Because these models do not include the high costs of finding and funding the numerous failures nor for promotion costs, any policies based on such models would lead to less variety and choice than we currently have. Record studios would be forced to take fewer chances and would only give record contracts to artists with a very high likelihood of success. Bruce Springsteen, as one example, would not likely have been allowed to record Born to Run, his make-or-break breakout third album, coming as it did after the poor performance of his first two albums.

Economists who fail to count these other expenses short-change their analysis and are likely to derive unrealistic conclusions. Exactly how low legitimate products can be priced while still allowing for the required monetary incentive for creation, and for finding new creations, is a very difficult question that has yet to be properly addressed. Nor is it likely that we are capable of addressing it. Normally, we rely on competition, or competition law, to ensure that prices are kept at a sufficiently low level, not on government fiat to decree the correct price.

An instructive variant of these models of limit price setting is given by Varian (2005). ${ }^{27}$ There, a monopolist must decide on the price to charge for his good, where consumers have two options - to purchase a unit of the good from the monopolist, or to join together in a 'sharing syndicate' and purchase a communal unit that is then shared among them. Clearly, the sharing syndicate is a close analogy to a situation in which copying occurs; for example, it can be thought of as being analogous to a group of file sharers of music MP3 files. The sharing, however, is a form of indirect appropriability. It is not difficult to see that the optimal size of each sharing syndicate is determined by the price that the copyright owner charges (it is assumed that no price discrimination is possible, so individuals are charged the same price as a syndicate). It is also not difficult to show that the copyright owner will always have the option to price the product such that the optimal sharing syndicate size is exactly 1 , that is, no sharing at all happens. However, such a possibility may not be optimal for the seller (or for society) - rather, it may be worthwhile for the seller to set a price such that some, but a limited amount, of sharing occurs in the final equilibrium and to spend fewer resources finding new creative talent. This really says little more than if the copyright owner were to sell at a price that did not cover the cost of paying, finding, and promoting creators, i.e. the competitive price, there would be no incentive for any competitors to enter the industry. The bottom line of the sharing models of the type expounded by Varian is that it is costly to reduce sharing, and this cost needs to be taken into account when setting the final price at which originals are to be sold.

Whether or not the trade-offs that exist in the pricing of the different formats for pre-recorded music are really properly understood in the real world is at best unclear. For example, take the case of the pricing of music CDs and music on cassette tapes. Although the former are by far the major format for pre-recorded music, cassette tapes still exist and are still sold with the same content as CDs. However, CDs are sold at much higher prices than are cassettes, although it might 
be the case that the costs of production of a CD are below those of a cassette. It would appear these days that blank write-once CDs are less expensive than blank cassettes (although that was not always the case), but it is not known whether the master-slave machines to produce CDs (which record at speeds faster than playback) are more or less expensive than master-slave machines to produce cassettes, which also record at faster speeds (which lowers the fidelity of the playback for cassettes but not for CDs). Nor do we know anything about packaging costs. Thus, we do not know whether tapes are sold more cheaply to engage in a form of price discrimination to cover possibly lower costs. It is clear that a full and proper study of the production costs and the price elasticity of demand for pre-recorded music in different formats would be most enlightening as to how these products can be (and have or have not been) optimally priced in a market in which copying exists.

\subsubsection{Digital Rights Management Systems}

The objective of limit pricing strategies is to attempt to reduce the price of originals in order that they can effectively preclude copies from coming to the market, a stratagem that seemed unlikely to be a happy solution for copyright owners. Other strategies exist with the objective of increasing the cost of copies, so that originals may once again compete with them on a more level playing field while still preserving the ability of copyright owners to pay for creative aspects of the industry.

Legal protection under copyright law can be thought of as one such option, since the possibility of litigation against copiers must be considered when the decision to copy or not is taken. Another option that makes copying more expensive is the use of anti-copying devices and mechanisms. For the case of digital media, these anti-copying mechanisms take the form of code and encryption written on the same device as the intellectual property and that prevents copying from taking place, or that requires some form of payment before a copy can be made. This is what is known as a digital rights management system (DRM) ${ }^{28}$ For the case of pre-recorded music CDs, the possibility of distribution on non-copyable disks exists, but in many countries this type of DRM vitiates some common consumer behaviours, such as the right of private copy and the defence against infringement known as 'fair use' (Scotchmer, 2005, p. 216). Of course, we also need to re-examine the purpose of fair use, which was often thought to be largely motivated because the costs of these transactions would be greater than the benefit from the transaction, thus making any transacting impossible. DRM holds the promise of substantially decreasing these transaction costs. If it did so, there may no longer be any justification for fair use, or at least some components of fair use.

Not only is DRM controversial due to the possibility that it may interfere with previously allowed behaviours, but there is also fear that it may lead to an inefficient and resource wasting technology race that typically ensues when hackers work at breaking through DRM, and other programmers work to strengthen them (Watt, 2000). Of course, this same concern exists for every form of theft protection, including locks, alarms, doors, security guards and the like. Whether the situation will be worse in the case of copyright is yet to be determined. 
On the other hand, copyrights are currently costly to protect using more traditional systems (at least for the case of copyrights in digital products like music) such as legal protection. The deterrent effect of lawsuits seems small, apparently due to the general (and correct) perception of a very tiny probability of actually being caught (Maffioletti and Ramello, 2004). ${ }^{29}$ It is perfectly possible that the use of DRM is a more efficient way of reducing copying than is the law; however, we have not yet seen this technology at work and thus a proper economic analysis of this cannot yet be carried out.

The power of the DRM technology is yet to be tested in these markets. Such technology appears to be quite successful in the case of satellite television, fairly successful in the case of DVDs, and unsuccessful in the case of CDs. It is almost certain that current CDs will need to be scrapped before a useful DRM technology can be put to use in the sound recording business since it provides no room for computer codes except those that are easy to defeat and/or likely to cause negative publicity. ${ }^{30} 31$

\subsection{Mechanisms to Replace Copyright}

The previous two subsections discussed mechanisms under which copyright holders can either eliminate or reduce copying, or reduce the harm from copying. There is, however, a third set of options, somewhat unrelated among themselves except for the fact that they are attempts to solve the problems of copying in other ways.

\subsubsection{Taxes on Copying Devices}

Almost any type of copying requires some sort of physical support (blank CDs and DVDs, MP3 players, computer hard disks, etc.), or at least a physical copying or 'replay' technology (software, CD and DVD burners, photocopiers, MP3 players, Internet connections, etc.). Since copying is entirely dependent upon these physical complements, it has often been suggested that it is fair to place a tax, or levy, on the sale price of these devices, with the objective of generating funds from which to compensate copyright holders for lost royalties from copying. Clearly, then, the more copying that goes on, the more blank supports will be sold, and the greater will be the revenue that is collected via levies. Thus, taxes on blank supports and technologies are one method with which to attempt to overcome the deleterious impacts of copying, although taxes have their own well-researched set of negative consequences.

If copying were a minor problem, taxes such as these could be considered a minor supplement to traditional copyright revenues, and that is how they were considered until recently. Now, however, they are often analyzed as complete replacements for the copyright system and that is why this section is listed under the heading of copyright replacement.

Each of the blank supports and copying technologies can, of course, be used for purely legitimate activities (storing and retrieving documents and graphics created by oneself, storing and retrieving legitimately purchased copyrighted material, etc.). 
Since the media taxes are paid by all users, independent of the use that is made, this is really nothing more than a means of passing the externality from copying onto users of these technologies who do not engage in copying of copyrighted material. ${ }^{32}$

There are circumstances where media taxes may provide a second-best solution to the problems of copying. Clearly, if rampant or massive copying cannot be controlled through normal market mechanisms then the media tax could indeed be an alternative manner in which royalty payments can be made. In reality, this interpretation of media taxes is very much akin to the use of blanket licensing by copyright collectives - one pays for the right to use a great many copyrights, although one will in all likelihood only ever use a small subset of the entire repertory. ${ }^{33}$

Recently, Oksanen and Valimaki (2005) have argued strongly in favour of media levies as an alternative compensation system, basing their analysis upon the particular case of the online music market in Finland. The extremely rapid advance of digital copying and sharing leads Oksanen and Valimaki to conclude that levies are perhaps the only viable solution to copyright compensation in the future.

Netanel (2003) takes a somewhat different view of the issue, making a clear distinction between copying for commercial purposes (piracy) and copying for noncommercial purposes. He states:

... unlike commercial piracy ... the noncommercial sharing and reworking of cultural expression in $\mathrm{P} 2 \mathrm{P}$ networks is a phenomenon to be celebrated, not repressed. It is fundamentally speech, not theft. The key is to find a means to compensate authors and copyright holders efficiently, without impeding $\mathrm{P} 2 \mathrm{P}$ file sharers' expressive activity. (Netanel, 2003, p. 83)

The 'key' that is proposed by Netanel is that non-commercial sharing should be countered by a levy charged upon Internet connections (a 'Noncommercial Use Levy'), which would be used to compensate copyright holders for copying of a strictly non-commercial nature. The underlying concept is to propose a system that, while denying copyright holders proprietary control over non-commercial file sharing and remixing, would entitle them to compensation for such uses.

This replacement of the market with a system based on taxes reaches its fullest expression in the work of Fisher (2004) who provides the flesh to hang on skeletons such as that put forward by Natenal. Fisher would prefer that revenues come from income taxes but would accept taxes on complementary goods. He also proposes a form for the regulatory devices needed to determine the distribution of the proceeds of such taxes (surveys of usage, such as that created by Neilsen for television in the United States, although it would require far more detail and a much larger sample since it would cover numerous copyright industries and many thousands of products). Unfortunately he is largely silent on the very thorny issue of determining the appropriate amount of revenues to be generated by such taxes, which is the strongest of several criticisms made in Liebowitz (2005c).

On balance, and considering the particular case of the music market, it would seem that the use of media taxes and levies is a possible way to provide 
compensation for creators if more traditional market mechanisms fail to do the job. However, determining the correct amount of any such tax is a completely separate issue that does not provide for an easy solution. It is clear that this solution is one that should only be seriously examined after other avenues have proven fruitless. Additional work in this area would, of course, be most welcome.

\subsubsection{Outright Sale (Buy-Outs) Instead of Royalty Payments}

The concept of rewarding creative efforts by granting the creator a limited monopoly (copyright) that would then provide the creator with the ability to turn downstream users into customers is really quite a novel idea. During the renaissance, as is very well known, a large number of extremely creative individuals (artists, playwrights, etc.) were employed under a system of patronage. Such a system is akin to the outright sale of the rights to a creation even before the creative efforts are exerted, something like a commission. It appears that the motivation for the patron was one of status more than financial gain. It is certainly possible to go back to such a system but since there has been no legal restriction on its use we can take its decline in popularity to indicate that the copyright system that evolved to take its place had superior characteristics. As copyright declines in value, however, it is possible that billionaires will commission numerous musical works to replace the decline brought about by file sharing although the authors of this paper find this an unlikely prospect.

A form of buy-out is in force today. Recording contracts specify that the creators of sound recordings make some minimum number of recordings (often seven) before the contract loses force. And these contracts also provide advances against royalties. So the record companies play the same role as patrons used to, except that they try to make a profit from these activities. In the patron system the amount of copying that goes on afterwards would not have been of concern if the patron was not in the business of selling copies.

Up-front sale of rights, or buy-outs are considered a valid option throughout the patent literature (see Kremer, 1998, for a well-known reference), ${ }^{34}$ but it is unclear that they would be a solution to the problem of copying. Kremer's solution was to hold auctions for intellectual products where the bidders would occasionally receive the item but where the government would get the item most of the time. The government would then put the product in the public domain, removing any underconsumption inefficiency. Private individuals would randomly receive the product so as to induce serious bidding; otherwise the amounts of the auction paid by the government will not resemble market values, which is an important consideration if the system is to promote efficiency.

Two problems arise with this type of system as applied to copyright, with the second being critical. Bidders have little incentive to put out the effort to correctly value the product when they have little chance of winning. More importantly, for the case of file sharing, bidders will have very low value for the product if file sharing is rampant and so such auctions would not be able to reveal the value of highly copied products such as sound recordings.

(C) 2006 The Authors

Journal compilation (C) 2006 Blackwell Publishing Ltd 


\subsubsection{Voluntary Contributions and Auctions (Bidding for Content)}

A small, largely unpublished, literature exists that suggests that copyright holders can achieve compensation by appealing to voluntary contributions from consumers (see, for example, Nadel, 2002, and Woodhead, 2000). This basically amounts to reliance upon 'tipping' as a source of revenue. Of course, tipping has long been known in the economic theory literature to be a seemingly irrational act, unless inter-temporal concerns are invoked - no one (with positive marginal utility for money) should ever give a voluntary tip unless by doing so it is thought that future service will be enhanced. Of course, the expectation is that the tipee knows who has been a high tipper and rewards that individual with superior service.

The case of creation of copyrightable material is a poor example where tipping would seem likely to work. The same performance occurs for all consumers, so no individual tipper gets the individual benefit of a better performance from a tip. Instead, everyone has complete anonymity in the process, providing a very strong incentive to free-ride. There is no doubt that some fans will be willing to pay and that some funds will be generated. But there is every reason to believe that this system will lead to far lower revenues than traditional copyright. After all, any copyright creator could have tried this in the past, and few have. The best-known instance where it was tried was Stephen King writing a novel chapter by chapter. If enough contributions came in he would continue the novel, so he provided stronger motivations than a completed work would have. Nevertheless, he gave up on the project when the revenues were not forthcoming at the rate he had hoped.

\subsubsection{Public Funding: Rewards and Prizes}

Finally, we come to the option of providing recompense to creators of copyrightable intellectual property via rewards and prizes, rather than by the grant of copyright. This type of system has long been touted as a reasonable alternative incentive mechanism for creative endeavours, at least for the case of innovation and patentable creations (see Wright, 1983, and Shavell and Van Ypersele, 2001, for classic references). There are many examples of great creations in history that were the direct result of a competition with a monetary prize for the winner (see Scotchmer, 2005, chapter 2), and so it is reasonable to at least consider if rewarding creation via prizes is a valid alternative to copyright in modern society.

In reality, it is difficult to think of a situation in which copyrightable creativity can be effectively rewarded by a publicly organized prize system, since copyrightable creation is not normally the result of thinking towards the solution of particular problems, such as could be posed as the challenge in a contest. However, there is certainly no reason why artists (and authors) who prove themselves to be successful cannot, as some sort of prize for this contribution to the stock of cultural goods, receive public funding in exchange for allowing their future creations to fall directly into the public domain. This seems very similar to the tax system mentioned above since taxes are government funding. If there were to be a difference it might be that artists would be put on the public payroll and asked to create their wares. 
Probably the closest example to something like this would be the arts departments in public universities. Some, including us, recoil in horror at the thought of our creative industries resembling the output of those institutions.

\section{Conclusions}

Aside from a general introduction to the topic of the economic theory of copyright, in this paper we have considered the published literature concerning two very important, and rather interrelated, aspects of the market for music. First, we were interested in studying exactly how copying has affected the final demand for music on legitimate markets. Second, we have considered the possible alternatives to the grant of copyright that could be used by the music industry to compensate artists and creators.

These two questions are interrelated because of copyright infringement, or 'piracy', in the market for pre-recorded music. Currently, the financial interests of creators are supposed to be protected by copyright, which deems copying without paying a royalty to be illegal. However, illegal or not, copying certainly occurs, and so we are faced with a situation in which copyright law is proving inadequate for its stated purpose, namely that of providing compensation and incentives for creation. Thus our interest in the effects of infringement upon legitimate sales stems from the need to know the true extent to which copyright law, as a mechanism for ensuring compensation and the correct incentives for creation, is failing.

We can find plenty of evidence that economic harm is indeed being done, in spite of the fact that new artists are emerging and existing artists continue to produce new recordings. This is not surprising as long as file sharing does not completely destroy the industry. Therefore, it would seem that some incentive to create still exists, in spite of the failure of copyright law to fully protect against copying.

The task of comparing the current situation with one in which copying did not exist is, however, a counter-factual argument that is very difficult to perform. Thus we can only state that although creative efforts in the realm of music are going ahead in spite of the existence of copying, the magnitudes of the estimated losses due to copying are likely to cause serious dislocations in the market.

How that affects social welfare depends on the value of these copies to the individuals that consume them and the value of the creative works lost to the decline in industry revenues, something that seems virtually impossible to know.

Our second question, that of the possible alternatives to copyright law, basically takes as granted that an alternative is in order, and looks at what the economics literature has had to offer. We have noted that all of the possible alternatives are likely second-best solutions to the problem of efficient creation and distribution of information products, where the market failure based on copying renders the first-best solution unworkable.

There are many theoretical options, but not all of them necessarily have any practical value. The possibilities that seem most likely to provide some ameliorative impact are DRM and taxes on blank supports. If there are better business models (using bundling) the industry should be able to discover these on its own and 
perhaps some economists can make some money helping to show them the way. Theories based on network effects, on tipping, or auctions seem most unlikely to provide useful guidance. Nevertheless, some of these alternatives are debateable to say the least, in the sense that they may or may not be politically and legally feasible, mainly due to the adverse effects that they imply for the rights of others (above all, music consumers and non-copiers).

\section{Notes}

1. Of course the proper division of the total set of allocatable rights between the creator and society in general (via fair use) has also been hotly debated in the literature. See, for example, Gordon (1982) and Posner (1992).

2. The difficulty in enforcement is only one of many issues concerning copyright that could be addressed although it is currently undergoing the most dramatic alterations. Ever since Arrow's seminal contribution (Arrow, 1962), the 'paradox of disclosure' has been widely cited - the fact that in order to properly assess the willingness to pay for intellectual property involves disclosure of the very property that is intended to be later purchased, thereby reducing the posterior market value. Gans et al. (2002) cite several other interesting problems in the effective marketing of intellectual products.

3. Independently to the 'utilitarian' argument for copyright, the rationale for copyright based on moral and natural rights has also been examined - see, for example, Becker (1993) and Gordon (1993). Still others have argued for copyright based on such aspects as the importance of free expression - see Fisher (1988) and Netanel (1996).

4. Informative treatments of the basic economics of copyright abound. For example, the interested reader could consult Landes and Posner (1989), Besen and Raskind (1991), Watt (2000, chapter 1), Cooter and Ulen (2003), and Landes and Posner (2003). Gordon and Bone (2000) is also a most invaluable text, and includes an extensive list of references.

5. The costs of creation are limited to the costs of the creator which include the opportunity cost as a central component. See Shapiro and Varian $(1999$, p. 3) for a short explanation of the cost structure of information products.

6. Also, it is often argued that by allowing a price above marginal cost, copyright confers monopoly power on the creator, and so there is an associated dead-weight loss to society as access to the protected creation is restricted. But free entry into these markets will prevent most creators from earning monopoly rents.

7. The seminal papers on the economics of copying are Liebowitz (1981), Liebowitz (1985) and Johnson (1985). See also the more recent paper by Belleflamme (2002).

8. Dynamic efficiency refers to the cumulative nature of creative efforts - when creators build upon existing creations. The issue of cumulative creation is also a hot topic in the economics of patent, where the basic issues are identical to the case of copyright. See Scotchmer (1991) for the seminal paper on this topic.

9. This is simply because we are faced with a huge asymmetric information problem we do not know the creator's utility function, or her opportunity costs, and neither do we know the willingness to pay of each individual consumer, or even the aggregate willingness to pay of the entire consumption sector. Hopefully, such empirical issues as these will be the subject of rigorous study in the near future. 
10. The few exceptions are those that argue for complete lack of need for copyright in favour of market based solutions (e.g. Boldrin and Levine, 2002). This literature will be reviewed more fully below.

11. Of course, the case for copyright to exist can also be justified on the existence of transactions costs. By allocating entitlement to authors (who are few) rather than users (who are many), copyright is designed to save on transactions costs of allowing exchange to take place, a familiar aspect of many other workable exchange systems (Holderness, 1985). This rationale for copyright is based on the idea that it is much easier for authors to create and then sell a work to potential users than it is for users to get together to convince authors to write a work. This has been discussed by Gordon (1992a), (1992b) and (1992c), among others.

12. In the early literature on copyright, much was said of the non-pecuniary motive for creation (see, for example, Plant, 1934, and Hurt and Schuchman, 1966). Clearly, if creation is not motivated by monetary recompense, then infringement may not crowd out creation at all, and may even clearly stimulate it. The more modern view of the rationale for copyright is firmly based upon the monetary motives behind creation.

13. Even more impressive figures can be found for the case of software copyright infringement (see, for example, the $8^{\text {th }}$ Annual BSA Global Software Piracy Study, published as Business Software Alliance 2003, in which the piracy rate (the percentage of installed software that does not have a valid user license) in the USA is $24 \%$, and in Vietnam it is $95 \%$ ).

14. Although, admittedly, CD collections can be the result of gifts and discount price purchases.

15. Maffioletti and Ramello also report other findings concerning the perceived probability of being caught copying, and the perceived illegality of copying.

16. In the United States this would be particularly true for surveys conducted after the much publicized and unpopular lawsuits brought against individual file-sharers by the recording industry.

17. For a general discussion concerning when legal mechanisms are or are not superior to other alternatives, see Galini and Scotchmer (2002).

18. One should not mistake a new technology which has the impact of removing property rights with a superior technology that replaces an inferior incumbent. File sharing is similar, in many ways, to a hypothetical 'physical matter transporter', such as the transporter in the 'Star Trek' series. Such a transporter, if it existed, might be used to replace many inferior shipping techniques, such as trucks and railroads. If, however, the transporter were mainly used by individuals to remove products from stores and place them into private homes without payment, this would not be a case of a superior technology replacing an inferior one. Instead this would be a clear market failure based on the inability to protect property rights and, carried to its extreme, might lead to the dissolution of the advanced economy.

19. The level of copyright protection that maximizes social welfare must meet the participation condition of the creator. As we have pointed out above, copyright protection also increases in some instances the costs of creation and this should be accounted for as well.

20. This paper builds on earlier work by Liebowitz (1981).

21. Of course, a network externality may also work in a negative direction - for example, the case of traffic congestion on a highway, where additional users impose an externality cost on all others. 
22. See also, for example, King and Lampe (2003), and Farrell (1994) who argues that the existence of network externalities is a valid reason why copyright law should be weakened.

23. Tours might increase CD sales because attendees are more interested in the music after hearing a concert. Alternatively, tours might increase sales due to the publicity surrounding the tour even if most of the additional sales come from individuals not attending the concert. In this latter case it is conceivable that concerts are actually a substitute for $\mathrm{CD}$ sales on the part of concert goers. In the former case raising the concert price might work as hoped. In the latter case it will not.

24. For example, Microsoft (among many others) offers free access to e-mail software, with a free individual account to anyone who wants one under hotmail.com. However, users of this service must endure the advertising banners that appear unsolicited as the software is used.

25. And it can be a good strategy too. For example, Lawrence Lessig offers his book 'Free Culture' as a pdf file for free on his website, and yet the hard-print version of the book maintains a privileged place among the best sellers on Amazon.com.

26. This is a possibility whenever copies have a transactions cost - direct costs of copying, inconvenience costs, and the implicit cost of consuming an inferior item.

27. See also the models in Bakos et al. (1999), and Varian (2000). Furthermore, Scotchmer (2005, pp. 219-23) offers a short model that captures most of the salient elements of sharing clubs.

28. Scotchmer (2005, chapter 7, section 3) offers a short introduction to DRMS as a protection mechanism for intellectual property.

29. Penalties paid by infringers sued by the RIAA are reportedly in the range of $\$ 3000$ and it is claimed these penalties largely cover the costs of the prosecutions, although if true we would expect to see prosecutions ramped up to a much larger scale than the current number of 15,000 that have occurred over the last few years.

30. The transition to a new hardware technology is usually motivated by some technical improvement that the user wishes (portability with cassettes, scratch free quality with CDs). In this case it is not clear that there is any new valuable gain so the audio industry might need to try bundling players with a group of CDs (say 6) that makes the price of a player almost zero, while also claiming some audio advantage, of course.

31. The Sony BMG 'Rootkit' fiasco, in November of 2005, whereupon putting a CD in a computer drive caused a virus-like product to be put on the hard-drive, resulting in enormous bad publicity, a botched product recall, and various lawsuits, is a case point.

32. Other problems can emerge also. For example, in Spain the copyright collective SGAE negotiated a media levy with the producers of blank CDs (i.e. not a regulatory measure introduced by law) that was to be charged at point of sale and then passed on to copyright holders via the collective. As soon as one blank support producer reneges on this deal (in order to then sell at a lower price than its competitors), then all blank CD producers will be forced to renege in order to stay in business. Thus this system can be seen to be a type of prisoner's dilemma that implies its eventual inoperability.

33. Of course, the restriction to a blanket license has also not gone without critique. See, for example, Besen and Kirby (1989) for a good account of how copyright collectives function, and also Kernochan (1985), and Tournier and Joubert (1986), for legal discussions on the use of blanket licensing. 
34. Also, Llobet et al. (2000) show how buy-out clauses can be an integral part of an efficient mechanism for rewarding cumulative creation.

\section{References}

Akerlof, G. et al. (2002) Amici curiae in support of petitioners. Eldred v Ashcroft, No. 01-618.

Arrow, K. J. (1962) Economic welfare and the allocation of resources for invention. In K. J. Arrow (ed.), The Rate and Direction of Inventive Activity (pp. 609-625). Princeton: Princeton University Press.

Asundi, J., Kazman, R. and Arunachalam, V. S. (2006) Examining change contributions in an OSS project: the case of the Apache Web Server Project. Working Paper, Center for the Analysis of Property Rights and Innovation.

Baker, M. J. and Cunningham, B. M. (2006) Court decisions and equity markets: estimating the value of copyright protection. Journal of Law and Economics forthcoming.

Bakos, Y. and Brynjolfsson, E. (1999) Bundling information goods: prices, profits and efficiency. Management Science 45: 1613-1630.

Bakos, Y., Brynjolfsson, E. and Lichtman, D. (1999) Shared information goods. Journal of Law and Economics 42: 117-155.

Becker, L. (1993) Deserving to own intellectual property. Chicago-Kent Law Review 68: $609-629$.

Belinfante, A. and Davis, R. (1979) Estimating the demand for record albums. Review of Business and Economic Research 14: 47-53.

Belleflamme, P. (2002) Pricing information goods in the presence of copying. In W. Gordon and R. Watt (eds), The Economics of Copyright: Developments in Research and Analysis (pp. 26-54). Cheltenham, UK and Northampton, MA: Edward Elgar.

Besen, S. (1987) New technologies and intellectual property: an economic analysis. RAND Report No. N-2601-NSF.

Besen, S. and Kirby, S. (1989) Compensating creators of intellectual property: collectives that collect. RAND Report No. R-3751-MF.

Besen, S. and Raskind, L. (1991) An introduction to the law and economics of intellectual property. Journal of Economic Perspectives 5: 3-27.

Besen, S., Kirby, S. and Salop, S. (1992) An economic analysis of copyright collectives. Virginia Law Review 78: 383-411.

Blackburn, D. (2004) Online piracy and recorded music sales. Working Paper, Department of Economics, Harvard University.

Boldrin, M. and Levine, D. (2002) The case against intellectual property. The American Economic Review 92(2): 209-212.

Bounie, D., Bourreau, M. and Waelbroeck, P. (2005) Pirates or explorers? Analysis of music consumption in French Graduate Schools. Paper presented to the Annual Congress of the Society for Economic Research on Copyright Issues, Montreal. Available at http://www.serci.org/documents.html.

Breyer, S. (1970) The uneasy case for copyright: a study of copyright in books, photocopies, and computer programs. Harvard Law Review 84: 281-351.

Business Software Alliance (2003) Eighth Annual BSA Global Software Piracy Study, 2003. Available at http://www.bsa.org/globalstudy/

Cheung, S. (1970) The structure of a contract and the theory of a non-exclusive resource. Journal of Law and Economics 13: 49-70.

Coase, R. (1979) Payola in radio and television broadcasting. Journal of Law and Economics 22(2): 269-328.

Conner, K. and Rumelt, R. (1991) Software piracy: An analysis of protection strategies. Management Science 37: 125-39. 
Cooter, R. and Ulen, T. (2003) Law and Economics. Reading, MA: Addison Wesley, Longman.

CPB Netherlands Bureau for Economic Policy Analysis (2000) Copyright protection: Not more but different. CPB Working Paper No. 122. The Hague: CPB Netherlands Bureau for Economic Policy Analysis.

David, P. A. (1993) Intellectual property institutions and the panda's thumb: Patents, copyrights, and trade secrets in economic theory and history. In M. B. Wallerstein, M. E. Magee and R. A. Schoen (eds), Global Dimensions of Intellectual Property Rights in Science and Technology (pp. 19-62). Washington, DC: National Academy Press.

Demsetz, H. (1970) The private production of public goods. Journal of Law and Economics 13: 293-306.

Easterbrook, F. (1991) Intellectual property is still property. Harvard Journal of Law and Public Policy 13: 108-109.

Farrell, J. (1994) Arguments for Weaker Intellectual Property Protection in Network Industries. Working Paper No. 94-11, 1-14. Centre for the Study of Law and Society, University of California.

Fine, M. (2000) Soundscan Study on Napster Use and Loss of Sales. Available at http://www.riaa.com.

Fisher, W. W. (1988) Reconstructing the fair use doctrine. Harvard Law Review 101: $1659-1795$.

Fisher, W. W. (2004) Promises to Keep: Technology, Law, and the Future of Entertainment. Palo Alto, CA: Stanford University Press.

Gallini, N. and Scotchmer, S. (2002) Intellectual property: When is it the best incentive system? Innovation Policy and the Economy 2: 51-78.

Gans, J., Williams, P. and Briggs, D. (2002) Intellectual Property Rights: A Grant of Monopoly or an Aid to Competition? Intellectual Property Research Institute of Australia Working Paper No. 07/02. Available at http://www.ipria.org.

Gayer, A. and Shy, O. (2005) Copyright enforcement in the digital era. CESifo Economic Studies 51(2-3): 477-489.

Ginsburg, J. C., Gordon, W. J., Miller, A. R. and Patry, W. F. (2000) Symposia: The constitutionality of copyright term extension: How long is too long? Cardozo Arts \& Entertainment Law Journal 18: 651-737.

Gordon, W. (1982) Fair use as market failure: A structural and economic analysis of the Betamax case and its predecessors. Columbia Law Review 82: 1600-1657.

Gordon, W. (1992a) Asymmetric market failure and prisoner's dilemma in intellectual property. University of Dayton Law Review 17: 853-869.

Gordon, W. (1992b) On owning information. Virginia Law Review 78: 149-281.

Gordon, W. (1992c) Of harms and benefits: Torts, restitution and intellectual property. Journal of Legal Studies 21: 449-482.

Gordon, W. (1993) A property right in self-expression: Equality and individualism in the natural law of intellectual property. Yale Law Review 102: 1533-1609.

Gordon, W. and Bone, R. (2000) Copyright. In B. Bouckaert and G. Degeest (eds), Encyclopaedia of Law and Economics, Vol. 2 (pp. 189-215). Aldershot: Edward Elgar.

Holderness, C. G. (1985) A legal foundation for exchange. Journal of Legal Studies 14: 321-344.

Hollander, A. (1984) Market structure and performance in intellectual property: The case of copyright collectives. International Journal of Industrial Organization 2: 199-216.

Hong, S. H. (2004) The effect of digital technology on the sales of copyrighted goods: Evidence from Napster. Working Paper, Stanford University.

Hui, K. and Png, I. (2003) Piracy and the legitimate demand for recorded music. Contributions to Economic Analysis and Policy 2(1): article 11. Available at http://www.bepress.com/bejeap/contributions/vol2/iss1/art11. 
Hurt, R. and Schuchman, R. (1966) The economic rationale of copyright. American Economic Review 56: 421-432.

IFPI (2003) IFPI Music Piracy Report 2003. Available at http://www.ifpi.org/sitecontent/library/piracy2003.pdf.

Johnson, J. and Waldman, M. (2005) The limits of indirect appropriability in markets for copyable goods. Review of Economic Research on Copyright Issues 2(1): 19-37.

Johnson, W. (1985) The economics of copying. Journal of Political Economy 93: 158-174.

Kernochan, J. (1985) Music performing rights organizations in the United States of America: Special characteristics, restraints and public attitudes. Copyright 11: 389410.

King, S. P. and Lampe, R. (2003) Network externalities, price discrimination and profitable piracy. Information Economics and Policy 15(3): 271-290.

Kitch, E. W. (2000) Elementary and persistent errors in the economic analysis of intellectual property. Vanderbilt Law Review 53: 1727-1741.

Koboldt, C. (1995) Intellectual property and optimal copyright protection. Journal of Cultural Economics 19: 131-155.

Kremer, M. (1998) Patent buyouts: A mechanism for encouraging innovation. Quarterly Journal of Economics 113: 1137-67.

Ku, R. S. R. (2002) The creative destruction of copyright: Napster and the new economics of digital technology. University of Chicago Law Review 69: 263-324.

Landes, W. and Posner, R. (1989) An economic analysis of copyright law. Journal of Legal Studies 18: 325-363.

Landes, W. and Posner, R. (2002) Indefinitely renewable copyright. University of Chicago, John M. Olin Law and Economics Working Paper No. 154.

Landes, W. and Posner, R. (2003) The Economic Structure of Intellectual Property Law. Cambridge, MA: Harvard University Press.

Liebowitz, S. J. (1981) The impact of reprography on the copyright system. Copyright Revision Studies, Bureau of Corporate Affairs, Ottawa.

Liebowitz, S. J. (1985) Copying and indirect appropriability: Photocopying of journals. Journal of Political Economy 93: 945-957.

Liebowitz, S. J. (2002) Policing pirates in the networked age. Cato Policy Analysis No. 438. Available at http://www.cato.org/pubs/pas/pa438.pdf.

Liebowitz, S. J. (2003) Back to the future: Can owners appropriate revenues in the face of new copying technologies? In W. Gordon and R. Watt (eds), The Economics of Copyright: Developments in Research and Analysis (pp. 1-25). Northampton, MA and Cheltenham, UK: Edward Elgar.

Liebowitz, S. J. (2004) The elusive symbiosis: The impact of radio on the record industry. Review of Economic Research on Copyright Issues 1(1): 93-118.

Liebowitz, S. J. (2005a) Pitfalls in measuring the impact of file-sharing on the sound recording market. CESifo Economic Studies 51(2-3): 435-473.

Liebowitz, S. J. (2005b) Economists' topsy-turvy view of piracy. Review of Economic Research on Copyright Issues 2(1): 5-17.

Liebowitz, S. J. (2005c) MP3s and copyright collectives: A cure worse than the disease? In W. Gordon, L. Takeyama and R. Towse (eds), Developments in the Economics of Copyright: Research and Analysis (pp. 37-59). Cheltenham, UK and Northampton, MA: Edward Elgar.

Liebowitz, S. J. (2006a) File-sharing: Creative destruction or plain destruction. Journal of Law and Economics 49(1): 1-28.

Liebowitz, S. J. (2006b) Testing File-Sharing's Impact by Examining Record Sales in Cities. Working Paper, University of Texas at Dallas.

Liebowitz, S. J. and Margolis, S. E. (2005) 17 Famous economists weigh in on copyright: The role of theory, empirics and network effects. Harvard Journal of Law and Technology 18(2): 435-457. 
Llobet, G., Hopenhayn, H. and Mitchell, M. (2000) Rewarding Sequential Innovators: Prizes, Patents and Buyouts. Working Paper 0012, CEMFI.

Maffioletti, A. and Ramello, G. B. (2004) Should we put them in jail? Copyright infringement, penalties and consumer behaviour: Insights from experimental data. Review of Economic Research on Copyright Issues 1(2): 75-89.

Mannering, F. (1994) Assessing the impacts of audio home copying restrictions. Quarterly Journal of Business and Economics 33: 30-41.

McCain, R. A. (1994) The Case for Minimal Protection of Intellectual Property Rights: Game Theoretic and Cost of Transaction Perspectives. Paper presented at the International Conference on the Economics of Intellectual Property Rights. Venice, October.

Michel, N. (2005) The Impact of Digital File Sharing on the Music Industry: A Theoretical and Empirical Analysis. Paper presented to the Annual Congress of the Society for Economic Research on Copyright Issues, Montreal. Available at http://www.serci.org/documents.html.

Mockus, A., Fielding, R. T., and Herbsleb, J. (2002) Two case studies of open source software development: Apache and Mozilla. ACM Transactions on Software Engineering and Methodology 11(3): 309-346.

Mockus, A., Weiss, D. M., and Zhang, P. (2003) Understanding and Predicting Effort in Software Projects. Proceedings of the 25th International Conference on Software Engineering (ICSE '03). Portland, USA.

Nadel, M. S. (2002) Questioning the Economic Justification for (and thus Constitutionality of) Copyright Law's Prohibition Against Unauthorized Copying: §106. Paper presented at the Annual Congress of the Society for Economic Research on Copyright Issues. Northampton, MA: Available at http://www.serci.org/documents.html.

Netanel, N. W. (1996) Copyright and a democratic civil society. Yale Law Journal 106: 283-387.

Netanel, N. W. (2003) Impose a noncommercial use levy to allow free peer-to-peer file sharing. Harvard Journal of Law \& Technology 17: 1-84.

Novos, I. and Waldman, M. (1984) The effects of increased copyright protection: An analytic approach. Journal of Political Economy 92(2): 236-246.

Oberholzer, F. and Strumpf, K. (2004) The Effect of File Sharing on Record Sales: An Empirical Analysis. Working paper.

Oksanen, V. and Valimaki, M. (2005) Copyright levies as an alternative compensation method for recording artists and technological development. Review of Economic Research on Copyright Issues 2(2): 25-39.

Peitz, M. and Waelbroeck, P. (2004) The effect of internet piracy on music sales: Crosssection evidence. Review of Economic Research on Copyright Issues 1(2): 71-79.

Pethig, R. (1988) Copyrights and copying costs: A new price theoretic approach. Journal of Institutional and Theoretical Economics 144: 462-495.

Plant, A. (1934) The economic aspects of copyright in books. Economica 1: 167-195.

Posner, R. (1992) When is parody fair use? Journal of Legal Studies 21: 67-78.

Posner, R. (2005) Intellectual property: The law and economics approach. Journal of Economic Perspectives 19(2): 57-73.

Rappaport, E. (1998) Copyright Term Extension: Estimating the Economic Values. Congressional Research Service, CRS Report for Congress. Available at http://countingcalifornia.cdlib.org/crs/pdf/98-144.pdf.

Rob, R. and Waldfogel, J. (2006) Piracy on the high C's: Music downloading, sales displacement and social welfare in a survey of college students. Journal of Law and Economics 49(1): 29-62.

Scotchmer, S. (1991) Standing on the shoulders of giants: cumulative research and patent law. Journal of Economic Perspectives 5(1): 29-41.

Scotchmer, S. (2005) Innovation and Incentives. Cambridge, MA: MIT Press. 
Shapiro, C. and Varian, H. (1999) Information Rules: A Strategic Guide to the Network Economy. Boston: Harvard Business School Press.

Shavell, S. and van Ypersele, T. (2001) Rewards versus intellectual property rights. Journal of Law and Economics 44(2): 525-548.

Siebrasse, N. and McLaughlin, J. D. (2001) Contested Markets and the Optimal Breadth of Copyright Protection: The Example of Surveyors' Plans of Survey. Available at http://www.spatial.maine.edu/tempe/siebrasse.html.

Smith, D. A. (1986) Collective administration of copyright: An economic analysis. Research in Law and Economics 8: 137-151.

Takeyama, L. (1994) The welfare implications of unauthorized reproduction of intellectual property in the presence of demand network externalities. Journal of Industrial Economics 17: 155-166.

Thorpe, J. and Rimmer, S. (1995) An economic approach to copyright reform. Australian Intellectual Property Law Bulletin 8(10): 125-128.

Tournier, J. and Joubert, C. (1986) Collective administration and competition law. Copyright 3: 96-103.

Turnbull, S. (1998) Should ownership last forever? Journal of Socio-Economics 27(3): $341-363$.

Varian, H. R. (2000) Buying, sharing and renting information goods. Journal of Industrial Economics 48(4): 473-488.

Varian, H. R. (2005) Copying and copyright. Journal of Economic Perspectives 19(2): $121-138$.

Warner Communications, Inc. (1982) Estimate of loss due to home taping: Tapers' reports of replacement. Internal Document.

Watt, R. (2000) Copyright and Economic Theory: Friends or Foes? Cheltenham, UK and Northampton, MA: Edward Elgar.

Watt, R. (2004) The past and the future of the economics of copyright. Review of Economic Research on Copyright Issues 1(1): 151-171.

Widdows, R. and McHugh, R. (1984) Taxing purchases of home tape recorders and supplies to compensate for copyright infringements: An econometric analysis of the role of economic and demographic factors. Journal of Consumer Affairs 18: 317-325.

Woodhead, R. (2000) Tipping - A Method for Optimizing Compensation for Intellectual Property. Available at http://tipping.selfpromotion.com.

Wright, B. D. (1983) The economics of invention incentives: Patents, prizes and research contracts. American Economic Review 73: 691-707.

Yoo, C. (2004) Copyright and product differentiation. New York University Law Review 79: 212-280.

Yoon, K. (2002) The optimal level of copyright protection. Information Economics and Policy 14: 327-348.

Zentner, A. (2005) File sharing and international sales of copyrighted music: An empirical analysis with a panel of countries. Topics in Economic Analysis \& Policy 5(1): Article 21. Available at http://www.bepress.com/bejeap/topics/vol5/iss1/art21.

Zentner, A. (2006) Measuring the effect of music downloads on music purchases. Journal of Law and Economics 49(1): 63-90. 